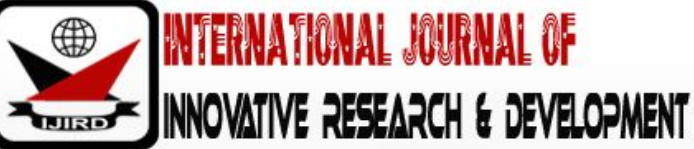

ISSN 2278 - 0211 (Online)

\section{Utilization of Monitoring and Evaluation and Performance of Digital Education Technology Project in Malawi}

\author{
Symon Manyenje Winiko \\ Ph.D. Candidate, Project Planning and Management, University of Nairobi, Kenya \\ Dr. John Mbugua \\ Lecturer, Department of Open Learning, University of Nairobi, Kenya \\ Dr. Dorothy Ndunge Kyalo \\ Senior Lecturer, School of Open and Distance Learning, University of Nairobi, Kenya
}

\begin{abstract}
:
Malawi's primary education is faced with challenges as a result of free primary education that was introduced in 1994. Enrolment rate is high making it difficult for teaching and learning to be executed. The Digital Education Technology (DET) Project was therefore introduced so as to enhance literacy and numeracy performance of standard one and two learners. Despite this intervention challenges in the sector are still persisting yet the project has monitoring and evaluation component. This paper investigated the extent to which monitoring and evaluation results influenced the performance of the DET project. The study adopted descriptive cross sectional correlational survey design where a questionnaire and interview guide were used as data collection tools from the personnel that participated in the implementation and monitoring and evaluation of the DET project. With $r=0.489, r^{2}=0.239$ and $F(1,183)=57.266$ at $p=0.001 \varangle 0.05$, the null hypothesis was rejected and concluded that utilization of Monitoring and Evaluation Results has a significant positive influence on the performance of DET project in Malawi.
\end{abstract}

Keywords: Dissemination of M\&E results, project performance, digital education technology

\section{Introduction}

Monitoring and Evaluation is critical in ensuring that an intervention is implemented as planned. As argued by Kyalo, Mulwa and Nyonje (2015) Monitoring and Evaluation is a continuous and periodic review whose rationale is to make sure that inputs, work schedules and outputs are proceeding as per project plan. Such a view is shared by Scheirer (2012) who contends that monitoring and evaluation results are utilized as evidence in decisions whose aim is to improve the implementation of the project plan and to establish that the project achieved its objectives. This is in line with United Nation Development Program (UNDP) (2009) description of monitoring and evaluation when they underscore that M\&E provides opportunities aimed at validating the logic of a project, its activities and their implementation. It is for this reason that M\&E results are fundamental in informing project decision making and learning by providing information bordering on the progress and status of the project undertaking. The ultimate goal of all this is to ensure the realization of a project that has performed according to the set objectives. Thus enhancement of project performance is the overall motivation of M\&E undertaking. This is consistent with UNDP (2009) assertion that the prime objective of M\&E is to enhance the achievement of project results.

It should be noted that for M\&E to have a desired effect on the performance of the project, M\&E results have to be utilized (Kyalo et al., 2015). This is consistent with program evaluation standards as developed by the Joint Committee on Standards for Educational Evaluation (2011) which among other standards calls for utility of M\&E findings. Thus utilization of M\&E results is non-negotiable if a project is to benefit from M\&E undertaking.

\subsection{Statement of the Problem}

Malawi is among the developing countries in the world with an estimated population of 17 million and a Gross Domestic Product (GDP) per capita of 320 USD (World Bank, 2017). Its ranking on Human Development Index (HDI) is 170 out of 186 (UNDP, 2013). In view of this there are financial challenges in the education sector leading to unimpressive education fundamentals. For instance the Southern and Eastern Africa Consortium for Monitoring Educational Quality (SACMEQ) survey of 2011 revealed that only $6 \%$ of standard 6 pupils in Malawi were able to meet grade level competencies on English Achievement test yet such a fit is supposed to be reached by standard 4 . In terms of numeracy performance among standard 6 learners the situation is equally not impressive as only $20.4 \%$ of the learners have reached the minimum level of numeracy (SACMEQ, 2017). Furthermore despite the fact that Malawi has gained significant strides in the area of pupil enrolment as a result of free primary education that was introduced in 1994, completion and repetition 
rates are worrisome. As reported by the Malawi Educational Management Information System (EMIS) (2016) completion and repetition rates are $50.9 \%$ and $27.6 \%$ respectively. These statistics show that there are challenges in Malawi's primary education sector. In this regard, Malawi has numerous projects whose aim is to improve the quality of education at primary school level. One of these projects is the Digital Education Technologies in particular Mobile Tablets aimed at boosting numeracy and literacy achievements for standards 1 and 2 pupils. Despite this project, learners' performance in these subjects is still a problem. The project however has M\&E component which is aimed at enhancing the performance of the project. The role that M\&E results in the project plays is not clear hence the need to investigate the influence of utilization of M\&E results on the project.

\subsection{Objective of the Study}

The objective of the study was to investigate the influence of Utilization of Monitoring and Evaluation Results on the performance of DET Project in Malawi's public primary schools.

\subsection{Hypothesis of the study}

In view of the research objective the following hypothesis was formulated.

- $\mathrm{H}_{1}$, Utilization of Monitoring and Evaluation Results has a significant influence on the performance of Digital Education Technology project in selected public primary schools in Malawi.

\section{Literature Review}

Utilization of M\&E results is associated with the use of M\&E results. Bhikoo and Louw-Potgieter (2013) as cited in Cloete et.al (2014) argue that evaluators usually spend much time in designing and implementing an evaluation that yields credible results but the findings are not used by stakeholders for programme improvement. This situation is opposed by Patton (2007) who argues that the essence of an evaluation is based on use of results (Mertens and Wilson, 2012). To this end Patton contends that an evaluation can be very well implemented with robust evaluation model and design but if its results are not used, it remains a bad evaluation. Thus utilization of M\&E results is critical and should be accorded consideration during the M\&E process (Alkin, 2013).

The importance of monitoring and evaluation results has been stressed by Adamchak et.al (2000) when they summarize reasons why monitoring and evaluation results are critical: Firstly results help to improve a program intervention as it puts the project staff in a learning mode regarding how the project is progressing in the context of what is going on right or wrong; a perspective which Richardson (2015) is in agreement with. Secondly M\&E results are instrumental in advocating for additional resources which are critical to the expansion of the program. This is because results shape donors decisions regarding the allocation of resources to competing programs (Stufflebeam, 2007). Thirdly, M\&E results are important as they contribute to the global understanding of what works. The world may know what is working and not working in relation to certain types of projects. By doing so, a contribution to the body of knowledge of how certain projects work is enhanced and other sectors wishing to implement similar programs may learn from it (Calley, 2011). The fourth point is that M\&E results are critical in informing decisions associated with program implementation changes. A stakeholders meeting aimed at discussing the results may agree on modifications regarding implementation process. This importance of M\&E results is in line with De Kool and Van Buuren (2004) when they state that "monitoring is frequently used as a measure to control the implementation of policy programs"(p.26). This entails that when failures are detected during the M\&E process, changes aimed at improving the program are made.

In view of the foregoing discussion, it can be implied that M\&E result utilization borders on provision of lessons to the project staff regarding how the program is working, how the project design is being adhered to, how project resources are being used and the program implementation changes. It is for this reason that the variable of M\&E result utilization will capture usefulness of results in improving project design, project implementation, project intervention and mobilization of resources as indicators.

The notion of result utilization is critical as it involves putting M\&E results into use. As argued by Patton (2007) an evaluation can be strong in terms of design and methodology however if the results are not used, it remains a bad evaluation. Indeed as the World Bank stipulates "the value of monitoring and evaluation does not come simply from conducting monitoring and evaluation or having such information available but from using the information to help improve government performance"p.1 (Mackay, 2007 cited in Barca and Carraro, 2013). This implies that the significance of monitoring and evaluation results utilization is non-negotiable and every effort should be put in place to ensure that M\&E results are used.

Despite M\&E result utilization being such an important element, scholarship that demonstrates the importance of result utilization in as far as project performance is concerned is limited. For instance Kithinji (2015) in a study entitled "Professional Development in Monitoring and Evaluation and Result Utilization in Meru Region in Kenya" established that professional development in monitoring and evaluation has a positive influence on result utilization. On the same note Gamba (2016) in a publication entitled "factors influencing the utilization of monitoring and evaluation findings in implementation of malaria control programs in Mukono District, Uganda" has established that result utilization is influenced by communication of monitoring and evaluation findings, timeliness and decision making. Both Kithinji and Gama used descriptive survey design and multiple regression analysis to determine the factors influencing result utilization hence the studies were methodologically strong. However both studies did not go further in determining what will happen to project performance if monitoring and evaluation results are used which is the area this study intends to explore in the context of DET project. It should be stated here that result utilization is not an end in itself but a means to promote project success. 
Elsewhere Adamchak, Bond, Maclaren, Magnan and Nelson (2000) have highlighted reasons why M\&E result utilization is important to a program. Firstly they contend that M\&E results help to improve project interventions as they put the project stuff in a learning mode as they understand how and why the program is working. Secondly they posit that M\&E results help the project stuff to lobby for extra resources in view of the fact that M\&E results are instrumental in shaping donors' decisions regarding allocation of resources in terms of what to fund. Thirdly M\&E results lead to changes in project implementation since these results are critical in early identification of problems which is a basis for timely corrective action. It is clear from the foregoing that the importances of result utilization are not grounded in primary data. Furthermore the magnitude of influence the above highlighted importances have on the DET project performance is not demonstrated. Thus improvements in the study design to provide for the quantification of the variables and their influence on a project can be a stronger methodology.

Various ways through which M\&E results can be used in a project have been articulated. M\&E results are used for validating the project logic to determine whether the theory of change is relevant to the project or not; also M\&E results bring to the fore emerging issues from project implementation including challenges, opportunities and risks thereby informing the strategies for managing the same (UNDP, 2009). In addition as argued by Preskill and Caracelli (1997) cited in Gildemyn (2014) M\&E results are used for program improvement and to provide information for decision making. As much as these aspects of result utilization are important in a project, it should be submitted that their influence on the performance of a DET project has not been addressed as the studies methodologically were not guided by positivism as a philosophical underpinning. As argued by Creswell (2014) positivism is associated with determining cause and effect. Thus using this approach the various ways through which results are utilized can have their influence on project performance determined. On this note, claims about the relevance of using M\&E results can be well grounded. Thus, in the absence of an investigation linking ways of M\&E result utilization and performance of DET project, M\&E will continue to be regarded as unaffordable luxury and an administrative burden (Hobson, Mayne and Halmiton, 2013).

In education, monitoring has been regarded as an instrumental undertaking. As argued by Korilaki (2006) in an article entitled "an enlightened use of educational monitoring in Greece" educational monitoring is critical to alleviating educational and social inequalities but this relies on both attainment and progress criteria as these bring to the fore different aspects of educational inadequacies. It is therefore clear from the foregoing that the use of M\&E results is central to alleviating educational disparities. It should however be submitted that such a claim was based on a general review of the Greek situation. There was no primary data that was collected to arrive at that claim. Furthermore the study is not clear as to how M\&E can lead to an alleviation of educational and social inequalities.

With respect to higher education the concept of higher education monitoring has been brought into monitoring and evaluation discourse to refer to a process that uses modern information technology to collect and analyze data continually as a basis for value judgments and scientific decision making regarding the status of higher education (Zhanjun, Waifeng and Jiangbo, 2016). Thus the purpose of higher education monitoring is for continual improvements and adaptation to systemic changes and governance reforms. This entails that higher education institutions that undergo higher education monitoring process may perform better. It should however be pointed out that the role of higher educational monitoring as a catalyst for institutional improvement has not been based on empirical investigation. It has mainly been based on the review of secondary scholarly resources. In this regard the empirical study on the relationship between use of higher educational monitoring results and project performance remains critical and it is this area that this study intends to explore.

In the context of manufacturing industries the relationship between environmental monitoring and organizational performance in terms of financial and marketing performance has been established. In a study by Green, Zelbst, Bhadauria and Meacham (2011) in which structural equation modeling was used it was established that environmental monitoring has a positive impact on organizational performance. An examination of the mechanisms behind that relationship borders on the utility of monitoring results as it is contended that monitoring provides information needed for the control of implementation of environmental sustainability programs. It should be pointed out that the study was rigorous in terms of methodology as structural equation modeling was used which is a robust statistical test hence the results are credible. However the study was in manufacturing industries which are profit oriented hence the situation might be different with DET project as it is non-profit making in nature. Nevertheless the study should be credited for empirically linking M\&E and project performance.

In view of the going, it is clear that assertions pertaining to the role of M\&E results utilization in the promotion of project performance have been advanced. However it should be pointed out that contrary opinions regarding the role of M\&E results in project performance have also been brought to the fore. For example Brandon and Singh (2009) as cited in Mertens and Wilson (2012) reviewed evaluation studies that focused on M\&E result utilization unfortunately they did not find evidence indicating that the evaluation findings were utilized. This suggests that claims of positive influence M\&E have on project performance might lack empirical grounding to substantiate.

\subsection{Utilization Evaluation Model as a Guide for the Study}

This evaluation model was proposed by Patton (1997) and it stipulates that evaluations should be judged based on their utility and actual use (Alkin, 2013). In this regard the model postulates that evaluation should be undertaken bearing in mind how it will affect use in terms of how real people in real world would apply evaluation findings. Thus the focus of utilization focused evaluation is on the intended users of evaluation as such the evaluation facilitator builds a relationship with these users so that they can determine the kind of evaluation they need. It should be pointed out that utilization focused evaluation does not advocate for any particular evaluation methodology, evaluation approach or a particular kind of use instead it helps intended users of evaluation to select appropriate content, model, methods, theory, 
and uses for their situation hence utilization focused evaluation is situational. It should be emphasized that intended users are likely to make use of evaluation if they understand and feel ownership of the evaluation hence they have to be actively involved in the evaluation process with the evaluator training the users in use. Active involvement of these users in the evaluation process is therefore critical.

The utility of monitoring and evaluation findings is therefore the whole mark of utilization focused evaluation model as such it calls for use of M\&E results to be given due consideration during M\&E undertaking. As stipulated by Patton (1997) no matter how robust M\&E exercise is, it will remain a useless endevour unless the results are put into use. Thus according to Utilization Focused Evaluation model, use of M\&E results is non-negotiable.

\subsection{Conceptual Framework}

Conceptual framework depicts the relationship between independent and dependent variables in a research study. Accordingly in this study utilization of M\&E results was the independent variable while performance of DET project was the dependent variable. This relationship is illustrated in Figure 1.

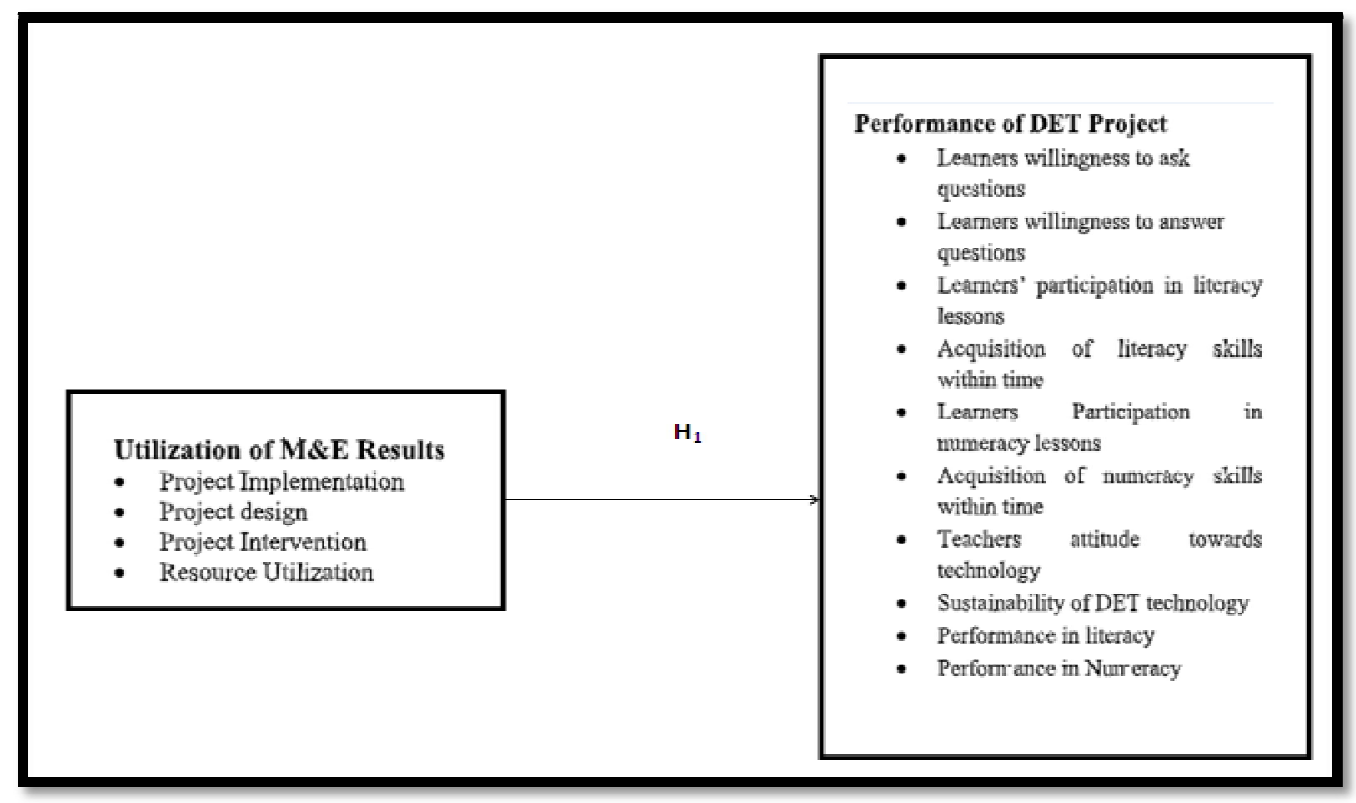

Figure 1: Conceptual Framework

Figure 1 demonstrates the perceived relationship between Utilization of M\&E results which is the independent variable and the performance of DET project which is the dependent variable. Utilization of M\&E results has been conceptualized in terms of use of M\&E results for enhancement of project implementation, project design, project intervention and project resource utilization. If the aforementioned uses of M\&E results are achieved, it is anticipated that performance of the DET project would improve in terms of learners' willingness to ask and answer questions, enhanced learners' participation in literacy and numeracy lessons, ability of learners to acquire literacy and numeracy lessons within the recommended time and improved sustainability of the project.

\section{Methodology}

The study employed a mixed methods approach and in particular a descriptive cross sectional survey design. In this regard both quantitative and qualitative data were gathered in order to address the research objective holistically. The target population was 456 personnel who took part in the implementation and monitoring and Evaluation of the DET project. Using Krecjie and Morgan 1970 criteria of determining sample size a total of 204 participants were included in the study. These participants were sampled using proportionate stratified random sampling strategy to ensure that all categories of the population were represented according to their size (Bryman, 2008). 204 questionnaires were therefore distributed to the respondents and 184 were returned representing a response rate of $89.75 \%$ which was appropriate as it was beyond $60 \%$ which is the minimum as proposed by Richardson (2005). Pilot testing of the questionnaires was undertaken based on respondents that were not sampled but from the same population. Reliability of the instruments was undertaken using Cronbach Alpha. With reliability coefficient of 0.808 and 0.846 for Utilization of M\&E results and performance of DET project respectively, the instruments were found to be reliable as the minimum reliability coefficient is 0.7 according to Gliem and Gliem (2003).

\section{Results and Discussion}

The objective of the research was to investigate the influence of Utilization of Monitoring and Evaluation Results on the performance of Digital Education Technology project in Malawi. In this regard performance of DET project was measured on a 5-point scale based on 10 parameters namely: learners willingness to ask questions, learners willingness to answer questions, acquisition of literacy skills within time, learners participation in literacy lessons, acquisition of numeracy skills within time, learners participation in numeracy lessons, teachers' interest in the use of digital education technology, schools' readiness to continue with the project after the project has phased out, improvement of literacy 
performance and improvement in numeracy performance. The Utilization of Monitoring and Evaluation results was also measured on a 5 point scale based on use of monitoring and Evaluation results improve project implementation, use of monitoring and evaluation results to improve project design, use of monitoring and evaluation results to improve project interventions and use of monitoring and evaluation to improve use of financial and material resources of the project as indicators.

\subsection{Distribution of Respondents by Gender}

The gender of the respondents was analyzed using frequencies and the results are presented in Table 1.

\begin{tabular}{|c|c|c|}
\hline Description & Frequency & Percent \\
\hline Male & 61 & 33.2 \\
\hline Female & 123 & 66.8 \\
\hline Total & 184 & 100 \\
\hline
\end{tabular}

Table 1: Distribution of the respondents by gender

The findings in Table 1 show that $66.8 \%$ of the respondents were females while $33.2 \%$ were males. This indicates that one gender dominates the involvement in the implementation and monitoring and evaluation of the DET project. The results suggests that females are active in the DET project than males hence the need to bridge the gender gap in the project.

42 Ages of the Respondents

The age of the respondents was assessed using range and mean as shown in the Table 2.

\begin{tabular}{|c|c|c|c|c|}
\hline Description & Minimum & Maximum & Mean & Std. Deviation \\
\hline Age & 19 & 58 & 35.082 & 10.39384 \\
\hline
\end{tabular}

Table 2: Age of the Respondents

Results in Table 2 indicate that the mean age of the respondents is 35.082 years. Furthermore the minimum age is 19 years while the maximum is 58 years. These findings mean that the respondents were mature enough to provide critical information regarding monitoring and evaluation and project performance issues. The standard deviation of 10.39384 means that the respondents were of varying ages. This entails that the DET project was accommodating such that it offered opportunities to all respondents of productive and energetic ages.

\subsection{Academic Qualifications of the Respondents}

The respondents were of varied academic standing. The distribution of the respondents as per their academic qualifications is presented in Table 3.

\begin{tabular}{|c|c|c|}
\hline & Frequency & Percent \\
\hline JC & 9 & 4.9 \\
\hline MSCE & 154 & 83.7 \\
\hline Diploma & 16 & 8.7 \\
\hline Bachelor & 4 & 2.2 \\
\hline PhD & 1 & 0.5 \\
\hline Total & 184 & 100 \\
\hline
\end{tabular}

Table 3: Academic Qualifications of the respondents

Table 3 shows that a majority 154 (83.7\%) of the respondents were Malawi School Certificate of education (MSCE) holders seconded by Diploma holders 16 (8.7\%). Junior Certificate holders (JC) came third with 4.9\% whereas Bachelor's Degree holders were at $2.2 \%$ while $1(0.5 \%)$ respondent had a PhD. All the respondents received training regarding the Digital Education Technology project and the associated implementation and monitoring and evaluation aspects of the project. This entails that the participants had information about the issue under investigation

\subsection{Performance of Digital Education Technology Project}

The study found it critical to measure the extent to which the Digital Education Technology project performed in Malawi. In order to achieve this 10 indicators were used and measured on a 5 point likert scale. The indicators were as follows: learners willingness to ask questions, learners willingness to answer questions, acquisition of literacy skills within time, learners participation in literacy lessons, acquisition of numeracy skills within time, learners participation in numeracy lessons, teachers' interest in the use of digital education technology, schools' readiness to continue with the project after the project has phased out, improvement of literacy performance and improvement in numeracy performance. The extent to which the DET project performed in relation to the aforementioned indicators is as per Table 4. 


\begin{tabular}{|c|c|c|c|c|c|c|c|c|}
\hline \multirow[t]{2}{*}{ Description } & \multicolumn{4}{|c|}{ Frequency and Percent } & \multirow[b]{2}{*}{ VGE } & \multirow[t]{2}{*}{$\mathbf{N}$} & \multirow[t]{2}{*}{ Mean } & \multirow[t]{2}{*}{ SD } \\
\hline & NA & $\mathrm{LE}$ & ME & GE & & & & \\
\hline \multicolumn{9}{|l|}{$\begin{array}{l}\text { The Project Enhanced } \\
\text { learners willingness }\end{array}$} \\
\hline to Ask questions & $\begin{array}{c}19 ; \\
10.3 \% \\
\end{array}$ & $\begin{array}{c}40 \\
21.7 \% \\
\end{array}$ & $\begin{array}{r}63 \\
34.2 \% \\
\end{array}$ & $\begin{array}{l}35 ; \\
19 \% \\
\end{array}$ & $\begin{aligned} 26 ; \\
14.1 \% \\
\end{aligned}$ & 183 & 3.04 & 1.1826 \\
\hline \multicolumn{9}{|l|}{$\begin{array}{l}\text { The Project Enhanced } \\
\text { learners willingness }\end{array}$} \\
\hline to answer questions & $\begin{array}{c}1 ; \\
5 \%\end{array}$ & $\begin{array}{c}14 ; \\
7.6 \%\end{array}$ & $\begin{array}{c}38 ; \\
20.7 \%\end{array}$ & $\begin{array}{c}64 ; \\
34.8 \%\end{array}$ & $\begin{array}{c}65 ; \\
35.3 \%\end{array}$ & 182 & 3.978 & 0.9631 \\
\hline \multicolumn{9}{|l|}{ The project helped learners } \\
\hline $\begin{array}{c}\text { to acquire literacy skills } \\
\text { within time }\end{array}$ & $\begin{array}{c}4 ; \\
2.2 \%\end{array}$ & $\begin{array}{c}22 ; \\
12 \%\end{array}$ & $\begin{array}{c}58 ; \\
31.5 \%\end{array}$ & $\begin{array}{c}65 ; \\
35.9 \%\end{array}$ & $\begin{array}{c}32 ; \\
17.7 \%\end{array}$ & 181 & 3.547 & 0.99121 \\
\hline \multicolumn{9}{|l|}{$\begin{array}{c}\text { The project enhanced } \\
\text { learners }\end{array}$} \\
\hline $\begin{array}{c}\text { participation in literacy } \\
\text { lessons }\end{array}$ & $\begin{array}{c}2 ; \\
1.3 \%\end{array}$ & $\begin{array}{c}9 ; \\
5.7 \%\end{array}$ & $\begin{array}{c}33 ; \\
20.9 \%\end{array}$ & $\begin{array}{r}49 ; \\
31 \%\end{array}$ & $\begin{array}{c}65 ; \\
41.1 \%\end{array}$ & 158 & 4.0506 & 0.98264 \\
\hline \multicolumn{9}{|l|}{$\begin{array}{c}\text { The project helped learners } \\
\text { to }\end{array}$} \\
\hline $\begin{array}{c}\text { acquire numeracy skills } \\
\text { within time }\end{array}$ & $\begin{array}{c}4 . \\
2.2 \% \\
\end{array}$ & $\begin{array}{c}26 ; \\
4.4 \% \\
\end{array}$ & $\begin{array}{c}56 ; \\
30.9 \% \\
\end{array}$ & $\begin{array}{c}59 ; \\
32.6 \% \\
\end{array}$ & $\begin{array}{c}36 . \\
19.9 \% \\
\end{array}$ & 181 & 3.5359 & 1.0353 \\
\hline \multicolumn{9}{|l|}{$\begin{array}{l}\text { The project enhanced } \\
\text { learners }\end{array}$} \\
\hline $\begin{array}{l}\text { participation in numeracy } \\
\text { lessons }\end{array}$ & $\begin{array}{l}1 ; \\
6 \%\end{array}$ & $\begin{array}{c}10 ; \\
5.6 \%\end{array}$ & $\begin{array}{c}22 ; \\
12.2 \%\end{array}$ & $\begin{array}{c}62 ; \\
34.3 \%\end{array}$ & $\begin{array}{c}85 ; \\
47.2 \%\end{array}$ & 180 & 4.222 & 0.90656 \\
\hline \multicolumn{9}{|l|}{$\begin{array}{c}\text { The project promoted } \\
\text { teachers }\end{array}$} \\
\hline $\begin{array}{c}\text { interest in the use of } \\
\text { technology }\end{array}$ & $\begin{array}{c}5 ; \\
2.7 \% \\
\end{array}$ & $\begin{array}{c}16 ; \\
8.7 \%\end{array}$ & $\begin{array}{c}35 \\
19.1 \% \\
\end{array}$ & $\begin{array}{c}43 ; \\
23.5 \% \\
\end{array}$ & $\begin{array}{c}84 \\
45.9 \% \\
\end{array}$ & 183 & 4.0109 & 1.1192 \\
\hline \multicolumn{9}{|l|}{ Schools were ready to } \\
\hline continue with the project & $\begin{array}{c}24 ; \\
13.2 \%\end{array}$ & $\begin{array}{c}52 ; \\
28.6 \%\end{array}$ & $\begin{array}{c}30 ; \\
16.5 \%\end{array}$ & $\begin{array}{c}36 ; \\
19.8 \%\end{array}$ & $\begin{array}{c}40 ; \\
22 \%\end{array}$ & 182 & 3.0879 & 1.0098 \\
\hline \multicolumn{9}{|l|}{$\begin{array}{l}\text { The project improved } \\
\text { literacy }\end{array}$} \\
\hline performance of learners & $\begin{array}{c}4 ; \\
2.2 \%\end{array}$ & $\begin{array}{c}16 ; \\
8.7 \%\end{array}$ & $\begin{array}{c}33 ; \\
17.9 \%\end{array}$ & $\begin{array}{l}75 ; 4 \\
0.8 \%\end{array}$ & $\begin{array}{c}62 ; \\
30.4 \%\end{array}$ & 184 & 3.8859 & 1.0098 \\
\hline \multicolumn{9}{|l|}{$\begin{array}{c}\text { The project improved } \\
\text { numeracy performance }\end{array}$} \\
\hline of learners & $\begin{array}{c}3 ; \\
1.6 \%\end{array}$ & $\begin{array}{c}7 ; \\
3.8 \%\end{array}$ & $\begin{array}{c}36 ; \\
19.7 \%\end{array}$ & $\begin{array}{c}75 ; \\
41 \%\end{array}$ & $\begin{array}{c}62 ; \\
33.9 \%\end{array}$ & 183 & 4.0164 & 0.91673 \\
\hline Composite Mean & & & & & & 184 & 3.79 & 0.71305 \\
\hline
\end{tabular}

Table 4: Performance of Digital Educational Technology Project

$\mathrm{NA}=$ Not at all, LE=Little Extent, ME=Moderate Extent, GE=Great Extent, VGE=Very Great Extent $\mathrm{n}=$ number of Respondents, $\mathrm{SD}=$ Standard Deviation

Table 4 shows that generally the DET project was perceived to have moderately performed since the indicators had means ranging from 3.04 to 4.22 measured on a 5-point likert scale. An examination of the frequencies showed that a majority of the respondents (with the highest being $47.2 \%$ and lowest being $14.1 \%$ ) felt that the DET project performed to a very great extent. Learners participation in numeracy lessons was viewed as the main aspect of DET project performance since it had a mean of 4.222 and SD of 0.90656 where 147 respondents rated this aspect of performance as great extent $(62 ; 34.3 \%)$ or very great extent $(85 ; 45.9)$ representing $80.2 \%$ of the respondents. Learners' participation in literacy lessons was rated second with a mean rating of 4.0506 and SD of .98264. This was followed by participants' conviction that the DET project improved learners' numeracy performance which had a mean of 4.0164 and SD of .91673. Promotion of teachers' interest in the use of technology came fourth with a mean of 4.0109 and SD of 1.1192 while learners' ability to answer questions came fifth with a mean of 3.978 and SD of 0.9631 . Participant conviction that the DET project had improved learner's literacy performance was rated sixth with a mean of 3.8859 and SD of 1.0098. Ranked seventh was leaners ability to acquire literacy skills within time which had a mean of 3.547 and SD of 0.9912 . This was followed by learners' ability to acquire numeracy skills within time which had a mean rating of 3.5359 and SD of 1.035. School readiness to continue with the DET intervention once the project is phased out came ninth with mean of 3.0879 and SD of 1.0098. Learners' ability to ask questions came last with mean of 3.04 and SD of 1.1826.

The composite mean of DET project performance was 3.79 with SD of .71305.This implies that the DET project overall was perceived to have performed to a moderate extent. 
Interviews that were conducted revealed that the project has done well in terms of arousing leaners interest in numeracy and literacy lessons. Thus learners' participation in these subjects was perceived to have increased as it was reported that the use of tablets is motivating to the learners such that the desire to go into the learning center to have numeracy and literacy lessons sometimes came from learners themselves. One project implementer hinted that "learners are interested in this project. Leaners find the mobile tablets quite enjoyable to the extent that they ask us to open the learning centers so that they can have lessons. Dropouts are also willing to come and patronize the learning centers."

However learners' willingness to use the tablets did not just come without challenges as at first they were reluctant to use the tablets thinking that they are blood sucking devices. One project coordinator summed it all "it was really difficult for the leaners to start using the tablets. With rumors of blood sucking in this country, learners and parents thought that the tablets are blood sucking devices. Some learners were crying and even urinating themselves upon being given the tablet but now with community sensitization all these misconceptions have gone. "Thus the project enhanced learners' participation in both numeracy and literacy but there were challenges on the part of the learners which in the long run were addressed.

In terms of teachers' interest in the technology, it was reported that the technology is good such that teachers are interested in it however time was a problem for a majority of teachers. One project coordinator reported that teachers are busy with teaching regular classes such that it is difficult for them to find time to use the technology. She added that the project has no special time table in the school such that it is embedded in the normal school time table making it difficult for teachers to attend to this technology.

The issue of sustainability of the project was put to the participants during the interview. It was reported by both M\&E officials and project coordinators that it is difficult for the project to continue once the funders have pulled out adding that the tablets are expensive such that the schools cannot afford to repair let alone buy new ones. One M\&E official hinted that "this is a very expensive technology. One tablet costs $\$ 200$. Schools are inadequately funded to buy these gadgets".

These findings contract a study by Karolcik, Cipkova and Kinchin (2016) in which they reported that digital education technology projects are failing because of teachers' lack of confidence in the use of technologies and resistance to change. Furthermore the findings are at variance with a claim made by Khaddage, Muller and Flintiff (2016) that the adoption of these digital education technologies in the formal classrooms has been not impressive as many teachers in schools and colleges are reluctant to allow their widespread access. The moderate interest of teachers in the DET project implies that headways are being made with respect to the success of digital education technology project. Additionally the overall average performance $(M e a n=3.79)$ of the DET project demonstrates that the project is moving in the right direction although more work needs to be done.

\subsection{Utilization of Monitoring and Evaluation Results and Performance of DET Project}

Utilization of M\&E results is an important aspect of the M\&E process as without utilization of results, M\&E exercise would be a futile exercise. It is therefore against this background that as the fourth objective, the study determined the extent to which utilization of M\&E results influenced the DET project. In order to arrive at this realization use of M\&E results to improve implementation of project activities, use of M\&E results to improve project design, use of $M \& E$ results to improve quality of project interventions and use of $M \& E$ results to improve use of project resources were used as indicators. These indicators were then measured on a 5 point scale and the results are presented in Table

\begin{tabular}{|c|c|c|c|c|c|c|c|c|}
\hline \multirow[t]{2}{*}{ Description } & \multicolumn{3}{|c|}{ Frequencies and Percentage } & \multirow[b]{2}{*}{ GE } & \multirow[b]{2}{*}{ VGE } & \multirow[t]{2}{*}{$\mathrm{n}$} & \multirow[t]{2}{*}{ mean } & \multirow[t]{2}{*}{ SD } \\
\hline & NA & LE & ME & & & & & \\
\hline $\begin{array}{l}\text { M\&E results were used to } \\
\text { improve implementation }\end{array}$ & & & & & & & & \\
\hline of project activities & $\begin{array}{c}5 ; \\
2.7 \%\end{array}$ & $7 ; 3.8 \%$ & $\begin{array}{c}27 ; \\
14.7 \%\end{array}$ & $\begin{array}{c}54 ; \\
29.3 \%\end{array}$ & $91 ; 49.5 \%$ & 184 & 4.1902 & 1.0036 \\
\hline $\begin{array}{l}\text { M\&E results were used to } \\
\text { improve }\end{array}$ & & & & & & & & \\
\hline the project design & $\begin{array}{c}10 \\
5.4 \%\end{array}$ & $25 ; 13.6 \%$ & $\begin{array}{c}44 ; \\
23.9 \%\end{array}$ & $\begin{array}{c}63 ; \\
34.2 \%\end{array}$ & $\begin{array}{c}42 ; \\
22.8 \%\end{array}$ & 184 & 3.5543 & 1.1439 \\
\hline $\begin{array}{l}\text { M\&E results improved the } \\
\text { quality of project }\end{array}$ & & & & & & & & \\
\hline interventions & $\begin{array}{c}4 ; \\
2.2 \%\end{array}$ & $16 ; 8.7 \%$ & $\begin{array}{c}38 ; \\
20.7 \%\end{array}$ & $\begin{array}{c}62 ; \\
33.7 \%\end{array}$ & $64 ; 34.8 \%$ & 184 & 3.9022 & 1.046 \\
\hline $\begin{array}{c}\text { M\&E results improved use } \\
\text { of }\end{array}$ & & & & & & & & \\
\hline $\begin{array}{l}\text { financial and material } \\
\text { resources }\end{array}$ & $\begin{array}{c}8 ; \\
4.3 \%\end{array}$ & $15 ; 8.2 \%$ & $\begin{array}{c}31 ; 16.8 \\
\%\end{array}$ & $\begin{array}{r}57 ; \\
31 \%\end{array}$ & $73 ; 39.7 \%$ & 184 & 3.934 & 1.1337 \\
\hline Composite Mean and SD & & & & & & 184 & 3.8951 & 1.0818 \\
\hline
\end{tabular}

Table 5: Utilization of Monitoring and Evaluation Results

NA=Not At all, LE=Little Extent, ME=Moderate Extent, GE=Great Extent, VGE=Very Great Extent, $\mathrm{n}=$ Number of respondents, $\mathrm{SD}=$ Standard Deviation 
As presented in Table 5 generally respondents were of the perception that M\&E results were utilized to a moderate extent with means ranging from 3.5543 to 4.1902.

A critical examination of the frequencies shows that majority of the respondents (with the highest being 49.5\% and lowest being 22.8\%) felt that M\&E results were used to a very great extent. Use of M\&E results to improve the implementation of project activities was perceived as the main use of M\&E results with mean of 4.1902 and SD of 1.0036 where 145 respondents rated this specific aspect of M\&E results utilization as great extent $(54 ; 29.3 \%)$ or very great extent $(91 ; 49.5 \%)$ thereby representing $78.8 \%$ of the respondents. This was seconded by use of M\&E results to improve use of project resources which had a mean of 3.934 and SD of 1.1337. Use of M\&E results to improve quality of project interventions came third with mean of 3.9022 and SD of 1.046. This was followed by use of M\&E results to improve project design which had mean of 3.5543 and SD of 1.1439.

The composite mean of Utilization of Monitoring and Evaluation results of the DET project was 3.8951 while SD was 1.0818. These results mean that respondents were of the view that M\&E results for the project were used to a moderate extent.

Interviews that were conducted with the project staff seem to resonate with the picture presented in table 4.10 as participants were generally in agreement that M\&E results are utilized. It was reported by a project coordinator at school level that M\&E results have led to the improvement of the project in general. He indicated that as a result of utilizing M\&E results, the design of the learning centers has changed to allow for more ventilation so that the Tablets can last longer. The pronunciation of some words by a teacher in the tablet has also changed in order to suit the local context. For instance the pronunciation of the word nyenyezi (star) was like nye-e-nyezi in the tablet yet the standard pronunciation in Chichewa language which is the national language of Malawi is Nyenyezi. That's M\&E results were used to improve the design of the project.

It was also reported that M\&E results have been used to improve the use of material resources in the project. For instance the headsets used to listen to the lessons in the tablet were being chewed by the learners thereby reducing their lifespan. With M\&E visits into the schools to see how the project is working the problem was noted and the positioning of the headset was changed such that learners do not get a chance to chew them.

These findings therefore contradict claims by evaluation theorists that utilization of M\&E results is a problem in many projects. For instance, Bhikoo and Low-Potgieter (2013) as cited in Clo ete et.al (2014) observe that a lot of time is invested in designing evaluations so as to yield credible results but the results are not always used by project stakeholders for programme improvement. Furthermore Brandon and Singh (2009) as cited in Mertens and Wilson (2012) reported that they did not find evidence of utilization of $M \& E$ results after reviewing evaluation studies that focused on utilization. Evidence presented in this study however suggests that M\&E results are used for project improvement. This is in line with the study conducted by Kithinji (2015) which found out that M\&E results are utilized to a moderately high extent amongst non-governmental organizations in Meru county of Kenya. It can therefore be claimed that financial resources that were used to bankroll the M\&E exercise of the DET project did not go down the drain.

\subsection{The Correlation between Utilization of Monitoring and Evaluation Results and Performance of DET Project}

The influence of Utilization of M\&E and the performance of DET project was established using a technique called Pearson Product Moment Correlation Coefficient. In this vein composite means of the explanatory and criterion variables were used to establish the relationship and the findings are as presented in Table 6

\begin{tabular}{|c|c|c|c|}
\hline & & $\begin{array}{c}\text { Performance of DET } \\
\text { Project }\end{array}$ & $\begin{array}{c}\text { Utilization of M\&E } \\
\text { Results } \\
\end{array}$ \\
\hline \multirow[t]{3}{*}{$\begin{array}{l}\text { Performance of } \\
\text { DET project }\end{array}$} & $\begin{array}{c}\text { Pearson } \\
\text { Correlation }\end{array}$ & 1 & $.489^{* *}$ \\
\hline & Sig. (2-tailed) & & 0 \\
\hline & $\mathrm{N}$ & 184 & 184 \\
\hline \multirow[t]{3}{*}{$\begin{array}{l}\text { Utilization of } \\
\text { M\&E results }\end{array}$} & $\begin{array}{c}\text { Pearson } \\
\text { Correlation }\end{array}$ & $.489^{* *}$ & 1 \\
\hline & Sig. (2-tailed) & 0 & \\
\hline & $\mathrm{N}$ & 184 & 184 \\
\hline
\end{tabular}

Table 6: Correlation between Utilization of Monitoring and Evaluation

Results and Performance of DET Project

**. Correlation Is Significant at the 0.01 Level (2-Tailed)

According to the findings in table 6, there is a moderate positive relationship ( $\mathrm{r}=489$ ) between Utilization of Monitoring and Evaluation Results and performance of DET project. Additionally the correlation between the two variables is statistically significant at $p=0.01 \varangle 0.5$. These results mean that Utilization of monitoring and evaluation Results was perceived to have a moderate contribution to the performance of DET.

\subsection{Test of Hypothesis}

In order to further determine the influence of utilization of M\&E results on performance of DET project a regression analysis technique was used to test the following hypotheses: 
- H0: Utilization of M\&E Results has no influence on the Performance of Digital Education Technology in Malawi.

- H1: Utilization of M\&E Results has influence on the Performance of Digital Education in Malawi.

In testing the hypothesis composite mean score of indicators of Utilization of Monitoring and Evaluation results was used as the independent variable. The composite mean of performance of DET project was at this juncture used as the dependent variable. The linear regression that was tested was $\mathrm{y}=\mathrm{a}+\mathrm{B}_{1} \mathrm{X}_{1}+\mathrm{e}$ where:

- $\quad \mathrm{y}=$ Performance of DET project

- $\mathrm{a}=$ constant

- $\mathrm{B}_{1}=$ Beta coefficient

- $\mathrm{X}_{1}=$ Utilization of Monitoring and Evaluation

- $\mathrm{e}=$ error term

The results of the regression analysis are presented in table 7.

\begin{tabular}{|c|c|c|c|c|c|}
\hline Model Summaries & R & R-Square & Durbin-Watson & \multicolumn{2}{c|}{$\begin{array}{c}\text { Unstandardized } \\
\text { Coefficient }\end{array}$} \\
\cline { 3 - 6 } & & & & B & Std.Error \\
\hline & 0.489 & 0.239 & 1.688 & & \\
\hline (Constant) & & & & 1.944 & 0.234 \\
\hline \multicolumn{2}{|c|}{ Utilization of M\&E results } & & 0.445 & 0.059 \\
\hline
\end{tabular}

Table 7: Utilization of M\&E Results and the Performance of Digital Education Technology Project $F(1,183)=57.266, p=0.001<0.05$

a. Dependent variable: Performance of DET project

b. Predictors: Utilization of M\&E Results

Results presented in Table 7 show that $R=0.489$. This means that Utilization of Monitoring and Evaluation results had a moderate influence on performance of the DET project in Malawi. The coefficient of determination ( $\left.\mathrm{R}^{2}\right)$ was 0.239 which implies that $23.9 \%$ variation in performance of the DET project can be explained by utilization of Monitoring and Evaluation Results. In this particular regard $76.1 \%$ of change in performance of the DET project was due to other factors outside the model. A beta value of 0.445 means that a unit increase of utilization of M\&E results contributes to $44.5 \%$ increase in performance of DET project. The model is statistically significant at $\mathrm{P}=0.001<0.05$. The Durbin-Watson test was 1.688 which is closer to 2 hence there was no autocorrelation. The $F$ ratio was significant based on the fact that $F(1,183)$ $=57.266, \mathrm{P}=0.001<0.05$. This implies that the influence of utilization of M\&E results on performance of DET project is statistically significant. At this juncture the null hypothesis was rejected and the alternative hypothesis accepted. It can therefore be concluded that utilization of M\&E results has a significant influence on performance of DET project in selected public primary schools in Malawi at 0.05 level of significance.

These findings are in line with Preskill and Caracelli (1997) cited in Gildemyn (2014) who argue that M\&E results are used for program improvement and to provide information for decision making. Thus this study has provided an empirical dimension to significance of utilizing M\&E results with particular focus on DET project. As presented in Table 4.23 utilization of M\&E results explains $23.9 \%$ change in performance of the DET project. Furthermore a unit increase of M\&E result utilization contributes $44.5 \%$ increase in performance of DET project. This is a manifestation of the fact that utilization of M\&E results is a critical process of M\&E.

The results also validate the argument advanced by Adamchak, Bond, Maclaren, Magnan and Nelson (2000) who contend that M\&E results help to improve project interventions as they put the project staff in a learning mode since they understand how and why the program is working. Improvement of project intervention was captured in this study as an indicator and it was established that M\&E results were used for this purpose to a moderate extent (mean=3.9022). The positive influence of utilization of M\&E results can therefore be partly attributed to the fact that project interventions were improved as a result of using M\&E results which in turn boosted performance of DET project. This contradicts observation by Bhikoo and Louw-Potgieter (2013) as cited in Cloete et.al (2014) who argue that evaluators usually spend much time in designing and implementing an evaluation that yields credible results but the findings are not used by stakeholders for programme improvement.

Though not in education Green, Zelbst, Bhadauria and Meacham (2011) established that environmental monitoring has a positive impact on organizational performance. Connectedly the World Bank argues that the value of monitoring and evaluation does not come simply from conducting monitoring and evaluation or having such information available but from using the information to help improve government performance (Mackay, 2007 cited in Barca and Carraro, 2013). Such positions have been echoed in this study as it has been empirically established that utilization of M\&E results positively influences performance of DET project.

The Joint Committee on Standards for Educational Evaluation (2011) stipulates that as one of the standards to be adhered to in Evaluation process, utility of evaluation has to be taken into consideration. Utility in this regard entails use of evaluation results for program performance. This study has therefore validated this standard empirically. With moderate execution of M\&E result utilization (mean=3.8951) performance of the DET project has improved. Project staff is therefore encouraged to use M\&E results in order to expedite project performance.

Michael Patton in his Utilization Focused Evaluation Model stipulates that evaluations should be judged based on their utility (Alkin, 2013). On the same note Patton argues that no matter how methodologically robust an evaluation is, if M\&E results are not used it is a bad evaluation. This study is therefore in line with these assertions. The study has 
established that M\&E results were utilized in the DET project and the positive influence that this utilization brought into the DET project has also been established. Thus this study has validated Patton's model of evaluation called Utilization Focused Evaluation (UFE).

\section{Conclusion}

It was the purpose of this study to determine the extent to which M\&E results were utilized in the DET project and it was found out that the utilization was to a moderate extent. Further investigation in terms of the influence of Utilization of M\&E results on the performance of DET project was undertaken and it was revealed that $r=0.489, r 2=0.239$, $F(1,183)=57.266$ at $p=0.001<0.05$, Utilization of M\&E results had a statistically significant positive influence on the performance of DET project. In this vein the study has established that $23.9 \%$ Change in the performance of DET project was explained by Utilization of M\&E results. Utilization of M\&E results should therefore be encouraged to improve the performance of DET project.

\section{Recommendation}

The study recommends that in order to maximize the benefits of M\&E process on project performance, the organization should intensify the utilization of $M \& E$ results. The study has established that M\&E results were used to a moderate extent hence there is still room for improvement.

\section{Further Studies}

The study has found out that M\&E results had a positive influence on performance of the DET project but were used to a moderate degree. It would be interesting for prospective researchers to establish factors that influence the utilization of M\&E results of educational projects. An understanding of these factors may inform the development of strategies that can be used to improve utilization of M\&E findings.

\section{References}

i. Adamchak, S., Bond, K., MacLaren, L., Magnani, R \& Nelson, K. (2000). A guide to Monitoring and Evaluating Adolescent Reproductive Health Programmes, Washington DC.

ii. Alkin, M., (2013). Evaluation Roots, A wider Perspective of Theorists' Views and Influences, Sage Publications, Inc, California.

iii. Barca, V., \& Carraro, (2013). Monitoring Implementation and Evaluating Performance, Experiences from Cash Social Assistance in Moldova ISSN 2042-1257 (Print) $\quad$ ISSN 2042-1265（Online) ISBN 978-1902477-14-5

iv. Bryman, A. (2008). Introduction to Social Research Methods, SAGE Publications, London.

v. Calley, N. (2011). Program Development in the 21st Century: An Evidence-Based Approach to Design, Implementation, and Evaluation, Sage, London.

vi. Cloete, F., Rabie, B., \& De Coning, C. (2014). Evaluation Management in South Africa and Africa, Sun Media, Stellenbosch.

vii. Creswell, J. (2014). Research Design: Qualitative, Quantitative and Mixed Methods Approaches, SAGE, London.

viii. De Kool, D., \& Van Buuren, A. (2004). Monitoring: Functional or Fashionable? Society and Economy, 26(2/ 3), 173193.

ix. Gamba, P. (2016). Factors affecting the utilization of monitoring and evaluation Findings in Implementation of Malaria Control Programmes In Mukono District, Uganda, Masters Dissertation, Uganda Technology and Management University.

x. Gildemyn, M., (2014). Understanding the influence of Independent Civil Society Monitoring and Evaluation at the District Level: A case of Study of Ghana. American Journal of Evaluation, 32(4), 507-524.

xi. Gliem, J. A., \& Gliem, R. R. (2003). Calculating, interpreting, and reporting Cronbach's alpha reliability coefficient for Likert-type scales. Midwest Research-to-Practice Conference in Adult, Continuing, and Community Education. Retrieved from https:/ / scholarworks.iupui.edu/ handle/ 1805/ 344.

xii. Green, K., Zelbst, P.,Bhadauria.,V,\&Meacham, J.(2011). Do environmental Collaboration and Environmental Monitoring Enhance Organizational Performance? Industrial Management and Data Systems, 112(2), 186-205.

xiii. Hobson, K., Mayne, R.,\& Hamilton, J.(2013). A Step by Step Guide to Monitoring and Evaluation, http:/ / www.lowcarbonwestoxford.org.uk.

xiv. Joint Committee on Standards for Educational Evaluation, (2011). The Program Evaluation Standards (3rd.ed.). Thousand Oaks, CA: Sage.

xv. Karolcik, S., Cipkova, E.,\& Kinchin,I, (2016). Teacher attitudes to professional development of Proficiency in the Classroom Application of Digital Technologies. Canadian Center of Science Education 9(4), 223-252.

xvi. Khaddage, F.,Muller, W.,\& Flintoff, K. (2016). Advancing Mobile Learning in Formal and Informal Settings via Mobile App Technology. Where to From Here, and How? Educational Technology and Society, 19(3), 16-26.

xvii. Kithinji, C., Kidombo, H, \& Gakuu, C. (2015) Professional Development in Monitoring and Evaluation and Result Utilization in Meru Region in Kenya. European Scientific Journal, 12(23), 309-328.

xviii. Korilaki, P. (2006). An enlightened use of Educational Monitoring in Greece. International Journal of Educational Management, 20(6), 415-438.

xix. Kyalo, K., Mulwa, A., \& Nyonje, R. (2015). Monitoring and Evaluation of Projects and Programs, A handbook for Students and Practitioners, Aura Publishers, Nairobi. 
xx. Mertens, D, \& Wilson, T. (2012). Program Evaluation Theory and Practice, A comprehensive guide, The Guilford Press, New York.

xxi. Richardson, G. (2015). Project Management Theory and Practice, Taylor \& Francis Group, Boca Raton

xxii. Richardson, J.T.E. (2005). Instruments for obtaining student feedback: a review of the literature. Assessment \& Evaluation in Higher Education30, no. 4: 387-415

xxiii. Scheirer, M. A. (2012). Planning Evaluation through the Program Life Cycle. American

Journal

of Evaluation, 33(2), 263-294.

xxiv. Stufflebeam, D., \& Shinkfield, A. (2007). Evaluation Theory, Models, and Applications, Jossey-Bass, San Francisco.

xxv. United Nation Development Program (2009) Handbook on Planning, Monitoring and Evaluating for Development Results, New York.

xxvi. Zhanjun, W.,Weifeng, Q.,\& Jiangbo, L. (2016). Data -Intensive Evaluation: The Concept, Methods, and Prospects of Higher Education Monitoring Evaluation, Chinese Education and Society, 49 , 86-98. 